\title{
The closed circuit rebreather (CCR): is it the safest device for deep scientific diving?
}

\author{
Alain Norro* \\ Royal Belgian Institute for Natural Sciences, Operational Directorate Nature, Gulledelle 100, B-1200 Brussels-Belgium
}

Received 12 August 2016; Accepted 20 September 2016

\begin{abstract}
The closed circuit rebreather (CCR) is not a new diving technology. From the late 1990s CCR units were commercially available in Europe, and increasingly more divers, and among them scientific divers, have been trained to use them. Even if many benefits exist for using CCR for all diving depth ranges, it is in the deep diving zone ranging from $50 \mathrm{~m}$ to $100 \mathrm{~m}$ of sea water where the main advantages to using this equipment exist. Using rebreathers does carry additional risks, and these must be mitigated to ensure safe usage. A standard for CCR scientific diving has existed for many years in the USA, and the levels of expertise within the European scientific diving community are now sufficient for a European standard to be established. National legislation for occupational scientific diving in many cases excludes CCR diving, which can limit its use for scientific purposes. This paper suggests that, where possible, legislations should be allowed to evolve in order to include this type of equipment where and when its use has direct advantages for both the safety and the efficiency of scientific diving. This paper provides a brief description of the fundamentals of closed circuit rebreather diving and outlines the benefits that its use offers diving scientists. Special attention is given to safety issues with the assertion that the CCR concept is, if strictly applied, the safest available technique today for autonomous deep scientific diving purposes.
\end{abstract}

Keywords: CCR scientific diving, mixed gas diving, diving safety, deep diving

\section{Introduction}

The closed circuit rebreather (CCR) is not a new diving technology. The concept of rebreathing gas underwater has been traced back to at least $900 \mathrm{BC}$ (Bozanic, 2010) and the modern-day design remains based on pre-WWI models, an example being the Fleuss rebreather that was made in 1879 .

* Contact author. Email address: alain.norro@naturalsciences.be
During both World Wars, many improvements were made to rebreathers based on their use for covert military actions.

The first electronic closed circuit rebreather, known as the Electrolung, was marketed in 1969. However, it was not until the late 1990s when electronic CCR started to be sold into the mainstream scuba diving markets, with the introduction of the BUDDY-INSPIRATION (now renamed the Ambient Pressure Diving's Inspiration CCR range). Modern CCRs for the European market are made by a small number of manufacturers, and their design and construction must follow the European Normative for rebreathers, EN 14143. The requirements contained within NBN EN 14143 (Bureau voor Normalisatie, 2013) are that rebreather technology using air as a diluent gas can be used to a depth of $40 \mathrm{~m}$, while Trimix/Heliair/Heliox diluents should be used below $40 \mathrm{~m}$ to the maximum depth covered by the EN standard of $100 \mathrm{~m}$. The technologies associated with CCRs continue to improve their functioning and use, with the latest developments including $\mathrm{CO}_{2}$ sensors in the breathing loop, bailout valves and solid state oxygen sensors (Sieber, 2014).

CCRs do not produce bubbles except for very few during the ascent phase of the dive. Their main advantage for diving physiology is that they permit the diver to breathe a constant partial pressure of oxygen during the dive. A sodalime filter removes the carbon dioxide produced by human metabolism while an electronic feedback system controls the partial pressure of oxygen $\left(\mathrm{ppO}_{2}\right)$ available in the breathing loop controlling oxygen addition into the loop automatically if required.

The three main advantages that CCRs offer the scientific diver are the significant lack of bubbles, gas efficiency and the optimised decompression that constant partial pressure of oxygen permits. The lack of bubbles has been shown to reduce the 
impact the diver has on the marine life being studied and improve the quality of science being undertaken in environments where the diver's bubbles would physically disturb the ecosystems being studied. Moreover, and from a safety perspective, CCR technology (when used according to the rules) is based on built-in redundancy and operational procedures that can enhance the safety of the diver.

However, CCR technology can add new risks, oxygen and/or carbon dioxide toxicities can occur very rapidly when the rebreather is not working properly or if the diver did not setup the equipment according to manufacturer specifications. Gas choice is of primary importance and proper training is the key factor for mitigating these risks. The equipment must be handled with care, and it is important that the diver adopts new approaches to how they undertake their diving when moving from using open circuit to CCR.

Much of the scientific use of CCR technology with mixed gases has been based on extending the underwater exploration range to limits that far exceed those possible when using typical scuba equipment. One of the first researchers to take advantage of the new technologies was the ichthyologist Richard Pyle from Honolulu, who used CCR equipment to study fish found in the mesophotic zone. It is not the purpose of this paper to provide a full list of all the studies that have employed CCRs, but many applications exists in behavioural sciences such as: Collette (1996) looking at fish behaviour; Lobel (2009) studying underwater acoustic ecology; and Tomoleoni et al. (2012) and Tinker et al. (2007) who used CCRs to facilitate the capture or recapture of sea otters. Moreover, Hinderstein et al. (2010), Sherman et al. (2009) and Rowley (2014) used the advantages provided by CCR deep mixedgas diving to study mesophotic coral ecosystems.

In Europe, it is widely accepted that diving for occupational scientific purposes should be limited to a maximum depth of $50 \mathrm{~m}$ when diving open circuit scuba using air. Beyond that depth, mixed gas technology is used in order to overcome the problems generated by nitrogen narcosis and to achieve acceptable gas densities that reduce the work of breathing (Mitchell and Doolette, 2013). The current situation in Belgium is that the scientific diver is advised to use rebreathers for diving as soon as there is a demonstrable added value for the scientist or for the quality of the science undertaken. Nevertheless, in many European countries, the use of mixed gas diving in support of underwater science is still in its infancy, and in some cases the use of rebreathers for occupational diving may not be permitted by law. In France, the capability to use rebreathers in scientific diving was initiated in 2014
(L'Agence nationale de sécurité sanitaire de l'alimentation, de l'environnement et du travail (Anses), 2014). However, the administrative and human resource challenges will probably be numerous and will more than likely be similar to the challenges outlined by Dokken (2006), who described how rebreathers became accepted for use in science diving in the USA.

For deep scientific diving, the CCR technology brings additional benefits over open circuit, such as reduced mixed gas requirements because of significantly higher gas efficiency leading to much lighter equipment to carry on expedition or use during the dive. In closed circuit diving, the breathing mixtures are different to open circuit and are usually set to deliver a lower equivalent narcotic depth (END), which allows better quality underwater work to be undertaken. CCR diving also brings a lower risk of making errors during decompression since the units alter the gas mixtures internally, negating the need for any physical gas switches by the diver. The negative aspects of CCR diving are the high costs of the rebreather unit itself, as well as the financial and time costs associated with the training required to be able to use them for the scientific research diving (Lang and McDonald, 2012). Careful planning is key to ensuring a safe diving activity, and special attention is needed when considering the bailout gas strategy for all aspects related to oxygen and carbon dioxide toxicities, gas density, inert gas narcosis decompression stresses.

The following section focuses on the safety issues related to the training, dive planning and operational use of mixed gas CCR technology when applied to scientific dives between $50 \mathrm{~m}$ and $100 \mathrm{~m}$ depth. The discussion also considers the practical application of dive planning rules, including gas choice and bailout strategies.

\section{Methods}

\subsection{Training}

All rebreather manufacturers require that training is taken prior to the purchase and use of their units by the diver. This training is the most important step to ensure the efficient and safe use of CCRs by a diver. If rebreather diving is being considered for a group of divers who will then work together in the future, then the group should consider undertaking the same training courses together. This approach may be time-consuming, as planning for a minimum of two years of preparation for a team prior to any scientific diving projects starting may be advisable. Rebreather training is commonly divided into a core course that is generic to all rebreather diving, and 
then a unit-specific course dedicated to the particular make and model of the rebreather that will be used. The diver is, therefore, only certified to use one type of rebreather. Should the diver change unit type, they would be required to undergo additional training that is specific to that new unit.

In addition to being unit-specific, rebreather training is also limited to a given depth of operation. Most training agencies have three levels of rebreather qualification; these tend to be defined by the maximum operating depth (MOD) that the training supports. The actual MOD limits differ slightly between training agencies but generally MOD-1 training supports rebreather diving where the diluent gas is air diving to maximum depths of $40 \mathrm{~m}$, the MOD-2 level uses trimix gas mixtures as the diluent to maximum depths of $60 \mathrm{~m}$, and the MOD-3 level uses a trimix diluent to a maximum depth of $100 \mathrm{~m}$. Once qualified at one level, the diver must usually achieve at least 50 hours of diving on the unit before starting the training for the next level.

Training usually begins with an initial introduction to the theoretical considerations of diving physics and gas physiology before the diver can begin to learn to use the diving unit in actual underwater operations. During the practical training, the diver is taught how to safely assemble and test the unit before diving. Because of the relative complexities of a CCR unit, evidence suggests that the diver is less likely to make mistakes during the setup if checklists are used to guide them through the process (Mitchell, 2014). In fact, many modern CCRs have checklists programmed into the display units with the diver having to follow them when preparing for a dive.

Once in the water, the diver is first trained in the normal use of the rebreather before being trained on actions to be taken in case of malfunction of various parts of the equipment. A rebreather is a more complicated piece of gear than normal scuba, and so equipment malfunction may be more likely to happen. Therefore, all rebreather diving should have an alternate source of gas - known as bailout gas - available. For the advanced MOD-2 and MOD-3 training levels, more consideration is given to adequate gas planning. This includes learning to control the psychological issues related to deep diving and escape procedures in case of rebreather malfunctions, and it may include training that is based on bailing out to open circuit diving. At the advanced training levels, more emphasis is given to considering the various possibilities to continue breathing from the main CCR breathing loop while safely solving problems that have occurred.

Following Lang and McDonald (2012), the nature of occupational scientific diving could mean that the training undertaken should consider including some of the more common sciencerelated tasks to be undertaken underwater. Ideally, the training should be delivered by a scientific diver who holds the appropriate CCR instructor certification. Some of the more important aspects of CCR training are dive planning, gas choice and bailout strategy for mixed gas diving.

\subsection{Dive planning}

The selection of the diluent gas is the first step when starting dive planning but is influenced or driven by knowing the dive site location and the planned maximum depth. The diluent gas is usually based on a mix of oxygen, nitrogen and helium (trimix) or oxygen and helium (heliox). The diluent gas could theoretically be a single inert gas or a mixture of inert gases, but it must, in practice and for safety reasons, contain some oxygen. The fraction of helium is defined when the END is known and the fraction of oxygen is defined by the maximum $\mathrm{ppO}_{2}$ acceptable at the MOD of the dive. The computation of the END in the breathing loop of a rebreather is somewhat more complicated than for open circuit and will always result in a shallower END than when using open circuit for a given fraction of nitrogen. In the CCR sector, this mix is often blended as heliair, which is a mixture of just helium and air but is always hypoxic (i.e. containing a fraction of oxygen that is less than $21 \%$ ). This is mainly because of operational simplicity, but also because oxygen control is provided anyway by the CCR.

After computing the END the resulting gas density must be taken into account in order to minimise the work of breathing. The work of breathing on a rebreather is influenced by its design (loop, $\mathrm{CO}_{2}$ canister, position of the counter lung) as well as by the gas density. Assuming that the diver has not modified the design of the breathing loop, the present recommended values for gas density in the loop are below $5.7 \mathrm{~g} \mathrm{~L}^{-1}$ (Antony and Mitchell, 2016). This corresponds to breathing air at $30 \mathrm{~m}$, with an absolute maximum limit of $6.7 \mathrm{~g} \mathrm{~L}^{-1}$ (air at $40 \mathrm{~m}$ ). Maintaining the gas density below these limits will mitigate the risk of $\mathrm{CO}_{2}$ retention and therefore hypercapnia.

It is a basic safety factor that bailout gases are always carried during a CCR dive. These are defined both in terms of the gas fractions of the three gases $(\mathrm{O}, \mathrm{He}$ and $\mathrm{N})$ and in the overall quantity of breathing gas required. To do this accurately, it is necessary to have estimates of the breathing rate of the diver expressed as their respiratory minute volume (RMV). Two different gases are usually planned: a 'bottom' gas and a 'decompression' gas. The fraction of oxygen on the bottom and decompression bailout gases are computed knowing the maximum $\mathrm{ppO}_{2}$ allowed at the MOD of the dive and the depth 
at which a decompression gas will be required. The fraction of helium in the bottom gas is computed using the permitted END, which also takes into account that the partial pressure of nitrogen should not build up at the moment of the gas switch and that an acceptable gas density is achieved. Similar calculations are needed for the fraction of helium, if any, in the decompression gas.

The volume of bailout gases to be carried is computed iteratively based on the basic dive parameters of planned bottom time and the resulting decompression obligation. However, the eventual volumes can be moderated depending on the choice of bailout strategy, which could be determined by a requirement that all divers are to dive completely self-sufficiently. Alternatively, some reliance could be allowed for a dive team bailout where gases could be shared, or even on gases that could be available at a decompression station deployed by the surface vessel.

After the selection of the diluent gas and bailout gases, the diver then needs to plan the amount of decompression that will need to be made and how the stops are staged. To do this, the CCR mixed-gas diver can use either dive tables or planning software that include decompression algorithm(s) for constant partial pressure of oxygen diving. Except the work done by the US Navy (Johnson and Gerth, 2001), there are not many tables that exist to support diving using constant partial pressures of oxygen in helium. VPLANNER or, more recently, MULTIDECO (Vplanner +Bulhman GF) developed by HHS Software are the most commonly used software for determining decompression. Some CCR manufacturers provide decompression computers that measure the breathing loop partial pressure of oxygen in real time and continuously compute decompression for a given diluent gas composition. A further alternative is to use unlinked mixedgas dive computers that allow set-points for constant $\mathrm{ppO}_{2}$ computations to be made. Doolette and Mitchell (2013) evaluated the present-day use of decompression algorithms by technical divers. They concluded that even though the commonly used decompression algorithms were not validated, unlike the US Navy tables (Johnson and Gerth, 2001), the technical diving community is performing many thousands of dives safely, even though the incidence of decompression sickness remains unknown. Doolette and Mitchell (2013) further concluded that it remains unknown if these unvalidated decompression procedures are optimal.

\subsection{Diving operations}

Deep diving is always challenging because of the many aspects to be considered during the planning process. Examples include dive location and weather; local administrative requirements; length of the proposed operation (a single dive or a series of dives); accommodation and catering related to the length of the operation; the management of the quantity and quality of the breathing gases; the dive team; the safety diver; underwater communications; and the decompression support both underwater and onboard, if required by the diving regulations or if surface decompression ( $\mathrm{SurD}$ ) is going to be used. Some of these aspects are addressed in European Scientific Diving Panel of the European Marine Board (ESDP, 2011).

Planning and executing CCR diving at work will vary considerably with the diving location. For example, planning and operations for cold water CCR diving will be different to that carried out in moderate or warm waters (Bardout, 2016). The target dive site could be, for example, a natural rock wall, a wreck or isolated rocks on the sea bed, and in each case the diving procedures will differ. This, in turn, could influence the type and size of support vessel. The support vessel should be able to provide enough gas in quantity and quality for the diving operation to be completed safely. Basing the work on CCR diving only will reduce the quantity of required gas drastically, permitting the use of smaller vessels and lighter loads. All breathing gases supplied should fulfil the European norm UNI EN 12021:2014 especially for the oil content in the air that is used in any oxygen-clean apparatus, including at the blending stage. Finally, it is extremely important to verify the actual final gas mixes that have been blended; best practice is to do this using more than one oxygen and/or helium meter.

The level of competency qualification required of the members of the CCR diving team is usually linked to local regulations. At European level, there are scientific diver qualifications overseen by the ESDP (2009). Unlike what exists through the American Academy of Underwater Sciences (AAUS, 2013), there is currently no specific competency level or standard recognised by the ESDP for rebreather diving in Europe. At the national level, an occupational scientific diving organisation may be responsible for establishing the acceptable standards. For example, in Belgium certification from known training agencies that are recognised by the manufacturer of the rebreather is accepted. The same approach could be adopted by the ESDP when a future standards supporting rebreather use in scientific diving across Europe are being considered.

\subsection{Safety of CCR mixed-gas deep scientific diving operations}

Scientific diving activities are known to be safer than any other kind of occupational diving, at least 
where decompression sickness is concerned (Dardeau et al., 2012). The study of Dardeau et al. (2012) was based on a dataset from the AAUS for the period 1998-2007; CCRs were in use by AAUS members during that period (Sellers, 2016). There is not much literature concerning the diving accidents resulting from the use of CCR, or any other types of rebreather outside the military sector (Louge et al. 2009). Trytkjo and Mitchell (2005), Lippman et al. (2011) and Fock (2013) examined the matter at different levels of approach. Fock (2013) examined deaths resulting from CCR dives within the period 1998-2010 and concluded that the risk of dying when using rebreathers appears to be 10 times what would be expected when using open circuit. The majority of the reported deaths were during what Fock defined as 'high risk dives' or which included 'high risk-behaviour'. Examples were entering the water with partially functional equipment or carrying insufficient bailout gases for an emergency.

Recently, Sellers (2016) extensively described the use of rebreathers in scientific diving operations at a number of American institutions. The study showed that rebreather dives represent less than $0.7 \%$ of the total numbers of dives operated. Based on the dataset examined, the non-fatal accident rate for rebreather diving was 6 for 15767 dives. Moreover, it was possible from those data to isolate dives that were deeper than $58 \mathrm{~m}$ (the AAUS maximum depth limit for diving on air only) but undertaken using mixed gases. No accidents were reported for those types of dive and, since 2011, these deep mixed-gas scientific dives were operated more using CCR than open circuit scuba.

Some rebreather models can log data during the dive (Parker, 2014). The information that tends to get logged is: $\mathrm{ppO}_{2}$, time, depth, voltage of the batteries, scrubber temperature (if measured), and the decompression obligations in addition to any set points selected by the diver and any alarms occurring during the dive. These data are valuable when examining what occurred in the case of any accident and are used to inform future training priorities.

\section{Discussion}

There are several rules or recommendations that CCR divers use when considering the correct fractions of oxygen and helium that make up the diluent gas to be used during a deep CCR dive. For instance, Lombardi and Godfrey (2011) recommend having a partial pressure of oxygen with a maximum $\mathrm{PO}_{2}$ of 1.30 bar at the MOD in the diluent, while Mount and Dituri (2009) recommend a maximum of 1.00 bar at MOD. The idea behind this maximal $\mathrm{ppO}_{2}$ in the diluent gas at MOD is simple. In the case of a hyperoxic loop, a diluent flush must be able to reduce its $\mathrm{ppO}_{2}$. Therefore, having a lower $\mathrm{ppO}_{2}$ in the diluent than the normal loop values of between 1.20 and 1.30 bar helps to reduce the resulting $\mathrm{ppO}_{2}$ quickly while also using a lower volume of gas. Having less oxygen in the diluent also reduces the overall density of the gas mixture.

The composition of the inert gas fraction of the diluent gas is a source of discussion that lacks any definitive conclusions. Lombardi and Godfrey (2011) chose END values that ranged from $15 \mathrm{~m}$ to $50 \mathrm{~m}$. Some of those values exceeded the recommendations of some training agencies, which propose an END value of $36 \mathrm{~m}$ (Mount and Ditury, 2009), or of some manufacturers, such as setting an END of $24 \mathrm{~m}$ for the depth of $100 \mathrm{~m}$ (Parker, 2016). Moreover, an END of $50 \mathrm{~m}$ results in a gas density that is well over the acceptable limit.

The narcosis effect of the diluent mix will further affect the judgment of the diver at depth, and this is certainly not desirable when both diving deep and working underwater. Not only will narcosis reduce the quality of the work, but in cases of an emergency the diver suffering narcosis will also have an increased reaction time with possible undesired outcomes. Diving with a diluent mix that does not satisfy the manufacturer's recommendations is dangerous behaviour and increases the risk associated with the dive.

The same simple rules also apply to the behaviour of the rebreather diver in relation to the oxygen cells used in the rebreather oxygen control system. The cells must be tested during any rebreather start-up and dive to confirm that they are working correctly. Making an oxygen flush at $6 \mathrm{~m}$ depth will give a good indication of the status of the cells. In the case of outdated cells (more than 18 months from their manufacturing date) or cells found to be out of working limits, the dive must be terminated and the cell(s) replaced before diving the unit again. Otherwise, there will be an increase in the risk taken for the dive.

The last point to be discussed is the correct choice and strategy for bailing out of a dive in an emergency. Bailout strategy can vary in two ways: the diver may choose to be fully self-sufficient on bailout gas, or the diving team of two or three divers may choose to share the bailout gas within the group, resulting in a lighter load during the dive for each individual.

In the first situation, the diver must carry throughout the dive a minimum of two extra cylinders - one bottom gas and one decompression gas. The size and number of bailout cylinders will depend on the 
planned dive profile. The quantity of gas required must address the worst-case scenario of a bailout. This will be when the failure of the rebreather occurs exactly at the end of the bottom time section of the dive - in other words, when the decompression time is maximal. In the case of a complete failure, for example where the breathing loop becomes flooded with water or an inefficient $\mathrm{CO}_{2}$ absorber, the diver must stop breathing from the rebreather loop and instead move onto open-circuit bailout. In less extreme events, such as total or partial failure of the electronics or the loss of a gas, the rebreather loop can still be dived in semi-closed mode, either on the diluent or on the bailout bottom gas. This mode type means that the dive can be safely completed using only a third of the gas quantity needed for the equivalent open circuit bailout.

When the self-sufficient bailout strategy is chosen, the diver can select a configuration that would include breathing the diluent gas as the first bailout gas, followed by an intermediate gas mixture. This would be then followed by breathing a decompression gas that could be used until reaching $6 \mathrm{~m}$ depth, where the loop could be breathed in pure oxygen mode, if not flooded or if the $\mathrm{CO}_{2}$ absorber continued to work properly; this is because electronic control would not be required at those depths. There would still be an option of breathing pure oxygen in open circuit mode in the case of complete failure of the breathing loop. This configuration could make use of $6.8 \mathrm{~L}$ carbon $300 \mathrm{bar}$ dive cylinders for the intermediate and decompression gas mixtures, and 7.0 L aluminium cylinders for the diluent and pure oxygen gases. However, when planning the volumes of gases required to support this configuration, consideration must be given to the fact that gases compressed to 300 bar do not follow the ideal gas laws. The Van der Waals interactions cannot be ignored above pressures of 240 bar and, instead, real gas laws apply and have the effect of reducing the assumed available volume of breathing gas.

Where it is planned that the bailout gases would be shared within the dive team, there is the obvious requirement that the divers remain together during the complete dive. Following Mount and Dituri (2008), a team bailout could be planned based on the three divers having sufficient bailout gases to support the ascent of 1.5 divers to the surface in open circuit mode. The three divers would each carry a pair of $11 \mathrm{~L}$ S80 cylinders: one cylinder would be filled with a bottom gas that should always be available to any of the three divers; the second would contain a decompression gas for two divers; and the third would be an intermediate gas for the third diver. The team would have to swap the cylinders between them during the ascent to support the diver having to bail out. The team bailout strategy is more optimal in terms of the number of cylinders that need to be carried per diver, but it does assume that only one unit during the dive has a problem requiring a full open circuit bailout.

The bailout ascent profile will depend on the composition of the bailout gases.

These are chosen in CCR deep mixed-gas diving following strict guidelines. The guidelines are based on the CCR diver having a bottom gas available that, when breathed on open circuit, would neither be hyperoxic or narcotic at the MOD of the planned dive. For example, a CCR dive that used air as the diluent to a maximum diving depth of $40 \mathrm{~m}$, could use air as the bailout gas at that MOD. When diving deeper and using a mixed gas the ideal is to have the maximum possible oxygen fraction in the bailout gas to enable a maximum $\mathrm{ppO}_{2}$ of 1.40 for the bottom gas and 1.60 for the decompression gas. For the remaining inert gas composition of the gas mixture, the strategy followed is to minimise the increase of $\mathrm{ppN}_{2}$ to a target amount while lowering the fraction of helium in the gas. The ideal situation is to replace the helium with oxygen while keeping the same amount of nitrogen at the gas switch. This is usually not practical for something like a $100 \mathrm{~m}$ depth dive with a bottom time of 20 min while only using two ascent gases. It would, however, be possible with three ascent gases.

In practice, for a dive of $20 \mathrm{~min}$ bottom time at $100 \mathrm{~m}$ depth, the gas choice should be as follows. The initial diluent being used for the dive could be $8 / 67$ ( $8 \%$ is the fraction of oxygen while $67 \%$ is the helium fraction, with the remaining part $25 \%$ being the nitrogen fraction of the mix; this mix would have an END of $23 \mathrm{~m}$ at $100 \mathrm{~m}$ ). On initiating a bailout, the diver could switch to a bottom gas of $13 / 65$, which during the ascent is then changed to a $25 / 45 \mathrm{mix}$ at $45 \mathrm{~m}$. At $20 \mathrm{~m}$, the diver could change to a 50/20 triox mixture (triox gases that are a trimix with an oxygen fraction higher than $21 \%$ ), followed ideally by a last switch at $6 \mathrm{~m}$ from triox to pure oxygen. In this case, the total decompression time during a bailout situation would be similar to the CCR time without bailout. Mount and Dituri (2008) published a table that can be used to compute the composition of bailout gases.

The scientific diving sector has the lowest incidence of decompression accident rates of all the industry sectors (Dardeau et al., 2012). This may, in part, be because of the education levels of the population in the sector, in addition to their ability to recognise when to not attempt or to terminate dives that are considered to be unsafe. There is, at 
present, no evidence to support that the accident rates will change as or if the mean diving depth increases. Fock (2013) suggested that CCR diving risk is reduced significantly when all the rules are respected and the use of the rebreather is well understood by the user. In most of the accident cases reported, the causal factor was human error and not rebreather failure.

\section{References}

American Academy of Underwater Sciences (AAUS). (2013). Standards for Scientific Diving, version 2013. Dauphin Island, American Academy of Underwater Sciences, 85pp.

L'Agence nationale de sécurité sanitaire de l'alimentation, de l'environnement et du travail (Anses). (2014). Effets sanitaires liés aux expositions professionnelles à des mélanges gazeux respiratoires autres que l'air dans le cadre des acytivités hyperbares. Rapport d'expertise, version scientifique. Anses, Maisons-Alfort, France. 352 pp.

Anthony G and Mitchell S. (2016). Respiratory Physiology of Rebreather Diving. In: Pollock NW, Sellers SH and Godfrey JM, (eds). Rebreathers and Scientific Diving. Proceedings of NPS/NOAA/DAN/AAUS Workshop, 16-19 February, Catalina Island, California, 66-79.

Bardout G. (2016). Manuel technique de plongée polaire. Paris, Ulmer, $240 \mathrm{pp}$.

Bozanic JE. (2010). Mastering rebreathers, $2^{\text {nd }}$ edition. Flagstaff, Best Publishing Company, 704pp.

Bureau voor Normalisatie (NBN). (2013). EN 14143: 2013. Norme Belge Enregistée. Appareil respiratoire: Appareils de plongée autonome à recyclage de gaz. Bruxelles, NBN. 61 pp.

Collette BB. (1996). Results of the Tektite Program: Ecology of coral-reef fishes. In: Lang M and Baldwin CC. (eds). Methods and Technique of Underwater Research. Washington, Smithsonian Institution, 83-87.

Dardeau MR, Pollock NW, McDonald CM and Lang MA. (2012). The incidence of decompression illness in 10 years of scientific diving. Diving and Hyperbaric Medicine 42: 195-200.

Dokken Q. (2006). Application of deep diving technology to scientific exploration. In: Lang MA and Smith NE. (eds.) Proceeding of the advanced scientific diving workshop. Washington, Smithsonian Institution, 143-147.

Doolette DJ and Mitchell SJ. (2013). Recreational technical diving part 2: Decompression from deep technical dives. Diving and Hyperbaric Medicine 43: 96-104.

European Scientific Diving Panel of the European Marine Board (ESDP). (2009). Common Practices for Recognition of European Competency Levels for Scientific Diving at Work. European Scientific Diving Panel of the European Science Foundation Marine Board. Brussels. 7pp. Available at: http://www.marineboard.eu/sites/ marineboard.eu/files/public/images/scientific\%20 diving\%20panel_cd1-91.pdf. <last accessed 05/10/16>.

ESDP. (2011). Guidelines for Scientific Diving from Large Research Vessels. ESDP Consultation Document no. 3, Brussels. European Marine Board, 7pp. Available at: http://www.marineboard.eu/sites/marineboard.eu/ files/public/images/scientific\%20diving\%20panel_cd391.pdf. <last accessed 05/10/16>.

Fock AW. (2013). Analysis of recreational closed-circuit rebreather deaths 1998-2010. Diving and Hyperbaric Medicine 43: 78-85.
Hinderstein LM, Marr JC, Martinez FA, Dowgiallo MJ, Puglise KA, Pyle RL, Zawada DG and Appeldoorn R. (2010). Theme section on "Mesophotic Coral Ecosystems: Characterisation, Ecology and Management". Coral Reef 29: 247-251.

Johnson TM and Gerth WA. (2001). 1.3 ATA $\mathrm{PO}_{2}-\mathrm{in}-\mathrm{He}$ Decompression tables for the MK16 MOD1 Diving: summary report and operational Guidance. Panama city, US Navy Experimental Diving Unit TR14-01.

Lang MA and McDonald CM. (2012). RB Colloqium recommandations. In: Lang M and Steller DL. (eds). Proceedings of the AAUS rebreather Colloquim, Monterey California, AAUS. 39pp.

Lippman J, Walker D, Lawrence C, Fock A, Wodak T and Jamieson S. (2011). Provisional report on diving-related fatalities in Australian waters 2006. Diving and Hyperbaric Medicine 41: 70-84.

Lobel PS. (2009). Underwater Acoustic Ecology: Boat noises and fishes behavior. In: Pollock NW. (ed). Diving for science. Proceedings of the AAUS $30^{\text {th }}$ Symposium, Dauphin Island, AAUS, 31-42.

Lombardi M and Godfrey J. (2011). In-water strategies for scientific diver-based examinations of the vertical mesophotic coral ecosystem from 50 to $150 \mathrm{~m}$. In: Pollock NW. (ed). Diving for science. Proceedings of the AAUS $30^{\text {th }}$ Symposium. Dauphin Island, AAUS, 13-21.

Louge P, Blatteau JE, Gempp E, Delprat P, Pontier JM and Hugon M. (2009). Epidemiologie des accidents de plongée avec appareils respiratoires a recyclage des gaz utilizes dans les armees francaises. A propos de 153 accidents repertories depuis 30 ans. Medsubhyp. 19(sup): 11-118.

Mitchell S. (2014). Rebreather Forum 3 Consensus. In: Vann RD, Denoble PJ and Pollock NW. (eds). Rebreather Forum 3. Durham, NC, AUS/DAN/PADI, 287-302.

Mitchell SJ and Doolette DJ. (2013). Recreational technical diving part 1: An introduction to technical diving methods and activities. Diving and Hyperbaric Medicine 43: 86-93.

Mount T and Dituri J. (2008) Exploration and mixed gas diving Encyclopedia. Miami Shores, the International Association of Nitrox Divers, 392pp.

Parker M. (2014). Quality assurance through real-time monitoring. In: Vann RD, Denoble PJ and Pollock NW. (eds). Rebreather Forum 3. Durham, NC, AUS/DAN/PADI, 137-147.

Parker M. (2016). Rebreather user Manual. Inspiration evo, xpd,evp. Helston, Ambient Pressure Diving, 196 pp.

Rowley SJ. (2014). Refugia in the 'twilight zone': discoveries from the Philippines. Marine Biologist 2: 18-19.

Sellers S. (2016). An Overview of Rebreathers in Scientific Diving 1998-2013. In: Pollock NW, Sellers SH and Godfrey JM. (eds). Rebreathers and Scientific Diving. Proceedings of NPS/NOAA/DAN/AAUS Workshop, 16-19 February, Catalina Island, California, 5-39.

Sherman C, Appeldoorn R, Carlo M, Nemeth M, Ruíz H and Bejarano I. (2009). Use of technical diving to study deep reef environments in Puerto Rico. In: Pollock NW. (ed). Diving for Science. Proceedings of the American Academy of Underwater Sciences $28^{\text {th }}$ Symposium. Dauphin Island, AAUS, 58-65.

Sieber A. (2014). Oxygen sensor technology for rebreathers. In: Vann RD, Denoble PJ and Pollock NW. (eds). Rebreather Forum 3. Durham, NC, AUS/DAN/PADI, 185-192.

Tinker MT, Costa DP, Estes JA and Wieringa N. (2007). Individual dietary specialization and dive behaviour in the California sea otter: Using archival time-depth data to detect alternative foraging strategies. Deep Sea Research 54: 330-42. 
Tomoleoni J, Weitzman B, Young C, Harris M, Hatfield B and Kenner M. (2012). Closed-Circuit Diving Techniques for Wild Sea Otter Capture. In: Steller D and Lobel L. (eds). Proceedings of the American Academy of Underwater Sciences $31^{\text {st }}$ Symposium. Dauphin Island, AAUS, 193-199.
Trytkjo B and Mitchell S. (2005). Extreme survival: a serious technical diving accident, SPUMS 35: 23-27.

Unifica zione Italiano (UNI). 2014. UNI EN 12021:2014, Respiratory Equipment - Compressed Gases For Breathing Apparatus. Unifica zione Italiano. 30pp. 